\title{
Proptosis: Clinical and etiological features
}

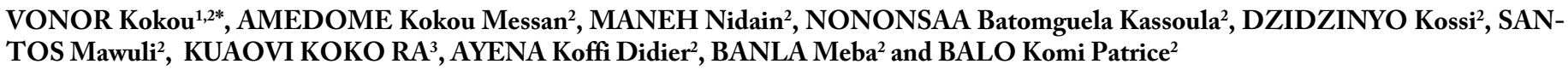

${ }^{1}$ Service d'Ophtalmologie du CHR Tsévié, Togo

${ }^{2}$ Département d’Ophtalmologie, Faculté des Sciences de la Santé, université de Lomé, Togo

${ }^{3}$ Cabinet AFIA, Lomé Togo

\begin{abstract}
Aims: To describe clinical and etiological features of proptosis.

Materials and methods: We have conducted a retrospective and descriptive study based on patient's records during 15 years, from January 2001 to December 2015. All patients went through a comprehensive ophthalmologic examination, and orbito-cerebral CT scan. T3, T4, TSH thyroid's hormone dosage was realized upon on the clinical request. The clinical features and the etiologies of proptosis were analyzed.

Results: During the period, 46 cases of proptosis were identified. The mean age was $41.2 \pm 18.8$ [1;79] years. There were 15 men against 31 women with a sex ratio of 0.48 . The proptosis was unilateral in 32 cases and bilateral in 14 cases. The proptosis was scaled as grade I was in 22 cases (47.8\%), grade II in 20 cases (43.5\%) and grade III in 4 cases (8.7\%). The proptosis was axial in 38 cases (82.6\%). It was painful in 21 cases (45.6\%). It was reducible in 23 cases (50\%) and pulsatile in one case (2.2\%). The etiologies of the proptosis were hyperthyroidism in 16 cases (34.8\%), orbital cellulitis in 12 cases (26.1\%), idiopathic orbital inflammatory disease in 9 cases $(19.6 \%)$, orbital tumors in 8 cases $(17.4 \%)$ and carotido-cavernous fistula in one case $(2.1 \%)$. Women were more involved by hyperthyroidism ( $81.3 \%)$, and it was associated with a bilateral proptosis (81.3\%), of grade II (68.8\%), axial (93.8\%) not painful (93.7\%) and reducible (93.8\%)
\end{abstract}

Conclusion: proptosis is a relatively frequent symptom that can reveal several diseases, some of them can be life threatening.

\section{Introduction}

Proptosis is an abnormal protrusion of the globe. It is the consequence of the development of a process inside the orbit or a shallow orbit. It is a relatively common condition and the etiologies are various. The purpose of this study is to describe the clinical and etiological features of proptosis.

\section{Materials and methods}

We have conducted a retrospective and descriptive study based on patient's records during 15 years, from January 2001 to December 2015. All patients included have received a comprehensive ophthalmologic examination, and orbito-cerebral CT scan. T3, T4, TSH thyroid's hormone dosage was realized upon the clinical orientation. The clinical features and the etiologies of exophthalmos were analyzed. The Epi info 7 software was use for the statistical comparison with a significance of $\mathrm{p}$ value under 0.05 .

\section{Results}

During the period, 46 cases of proptosis were identified. The mean age was $41,2 \pm 18.8[1 ; 79]$ years. There were 15 men against 31 women with a sex ratio of 0.48 . The proptosis was unilateral 32 cases $(69.6 \%)$ and bilateral in 14 cases (30.4\%). The proptosis was scaled as grade I in 22 cases $47.8 \%$, grade II in 20 cases or $43.5 \%$ and grade III in 4 cases is $8.7 \%$. proptosis was axial in 38 cases $(82.6 \%)$, painful in 21 cases $(45.6 \%)$, reducible in 23 cases (50\%) and pulsatile in one case (2.2\%). Etiologies of proptosis were dysthyroidism in 16 cases $(34.8 \%)$, orbital cellulitis in 12 cases $(26.1 \%)$, idiopathic orbital inflammatory disease in 9 cases $(19.6 \%)$, orbital tumors in $8(17.4 \%)$ and a case of carotido-cavernous
Fistula (2.1\%). Women were more involved by dysthyroidism $(81.3 \%)$ and it was associated with a bilateral proptosis $(81.3 \%)$, of grade II (68.8\%), axial (93.8\%), not painful (93.7\%) and reducible (93.8\%). Table 1 summarizes the characteristics of the proptosis according to the etiologies.

\section{Discussion}

The suspicion of proptosis requires confirmation by an exophtalmometer of Hertel or a Ludde rule or by CT scan or MRI. We decided to confirm cases of proptosis in this study by CT scan because it offers in the same time an etiologic investigation. The characteristics of proptosis contribute to determine their etiology. Bilateral proptosis can lead to inflammatory processes like hyperthyroidism or sometimes to lymphoma or metastasis. In our study, the proptosis was axial in $82.6 \%$. The axial character of the proptosis indicates the space area occupied by lesions within the muscle cone. The reducibility of the proptosis has poor clinical value, but can induce an oculo-cardiac reflex [1]. Pain is a cardinal sign of inflammation and it is found mainly in the cellulitis, hyperthyroidism, and neoplasm. A case of proptosis in our study was pulsatile. Pulsation is associated with a bruit and it's synchronous to

Correspondence to: Dr. VONOR Kokou, Service d'Ophtalmogie CHR Tsévié, Faculté des Sciences de la Santé de l'Université de Lomé, Togo. BP 13648, Lomé Togo; E-mail: benvonor@gmail.com

Key words: proptosis, hyperthyroidism, orbital cellulitis, orbital tumors

Received: January 10, 2017; Accepted: February 07, 2017; Published: February 10,2017 
Table 1. Characteristics of proptosis according to etiologies.

\begin{tabular}{|c|c|c|c|c|c|c|c|c|c|}
\hline & \multicolumn{3}{|c|}{ Grade n(\%) } & \multicolumn{2}{|c|}{$\operatorname{Sex} n(\%)$} & \multirow{2}{*}{$\begin{array}{l}\text { Unilateral } \\
\text { n(\%) }\end{array}$} & \multirow{2}{*}{$\begin{array}{l}\text { Axial } \\
\text { n(\%) }\end{array}$} & \multirow{2}{*}{$\begin{array}{c}\text { Painful } \\
\text { n(\%) }\end{array}$} & \multirow[t]{2}{*}{ Reduciblen(\%) } \\
\hline & $\mathbf{I}$ & II & III & $\mathbf{F}$ & $\mathbf{M}$ & & & & \\
\hline Dysthyroidism $(\mathrm{N}=16)$ & $11(68,8 \%)$ & $5(31,3 \%)$ & $0(0 \%)$ & $13(81,3 \%)$ & $3(18,7 \%)$ & $3(18,5 \%)$ & $15(93,8 \%)$ & $1(6,3 \%)$ & $15(93,8 \%)$ \\
\hline Orbital cellulitis $(\mathrm{N}=12)$ & $4(33,3 \%)$ & $5(41,7 \%)$ & $3(25 \%)$ & $9(75 \%)$ & $3(25 \%)$ & $12(100 \%)$ & $11(91,7 \%)$ & $12(100 \%)$ & $1(8,3 \%)$ \\
\hline $\begin{array}{l}\text { Idiopathic Orbital Inflammatory } \\
\text { disease }(\mathrm{N}=9)\end{array}$ & $6(66,7 \%)$ & $3(33,3 \%)$ & $0(0 \%)$ & $5(55,6 \%)$ & $4(44,6 \%)$ & $9(100 \%)$ & $8(88,9 \%)$ & $5(55,6 \%)$ & $6(66,7 \%)$ \\
\hline Orbital tumors $(\mathrm{N}=8)$ & $1(12,5 \%)$ & $6(75 \%)$ & $1(12,5 \%)$ & $4(50 \%)$ & $4(50 \%)$ & $8(100 \%)$ & $3(37,5 \%)$ & $3(37,5 \%)$ & $0(0 \%)$ \\
\hline Carottido-cavernous Fistula & $0(0 \%)$ & $1(100 \%)$ & $0(0 \%)$ & 0 & 1 & $1(100 \%)$ & $1(100 \%)$ & $0(100 \%)$ & $1(100 \%)$ \\
\hline Total $(\mathrm{N}=46)$ & $22(47,8 \%)$ & $20(43,5 \%)$ & $4(8,7 \%)$ & $31(68,9 \%)$ & $15(32,6 \%)$ & $32(69,6 \%)$ & $38(82,6 \%)$ & $21(45,6 \%)$ & $23(50 \%)$ \\
\hline
\end{tabular}

the pulse in the case of carotido-cavernous fistula. Proptosis in scaled by orbito-cerebral CT scan trough the oculo-orbital index. An index between 70 and 100, correspond to Grade I, grade II correspond to an index equal to 100 , and for grade III the index is above 100 .

The etiologies of the proptosis in our study are dysthyroidism in 16 cases $(34.8 \%)$, orbital cellulitis in 12 cases $(26.1 \%)$, idiopathic orbital inflammatory disease in 9 cases $(19.6 \%)$, orbital tumors in $8(17.4 \%)$ and a case of carotido-cavernous Fistula (2.1\%). Dysthyroidism is the most frequent cause of the proptosis [2]. In our study, characteristics of thyroid orbitopathy are the same in the literature [3-5]. In about a quarter of the cases, proptosis can be unilateral and sometimes precedes the dysthyroidism [1], a situation which could lead to misdiagnosis. In our study we have found $18.7 \%$ of cases of unilateral exophthalmos linked to dysthyroidism.

Orbital cellulitis was the second cause of proptosis in our study with $26.1 \%$ of cases. In our practice, orbital cellulitis reveals a problem of early consultation and diagnosis with the risk of complications such as cavernous sinus thrombophlebitis, brain abscess and sometimes deaths [6,7]. The idiopathic orbital inflammatory disease represented $19.6 \%$ of cases of proptosis in our study. The CT scan imaging does not highlight a localized tumor and the diagnosis is confirmed by it regression with systemic steroid treatment.

Orbital tumors accounted for 17.4 percent of cases of proptosis. In childhood, rhabdomyosarcoma, and benign tumors like angioma or cyst are common. In adults less than 60 years, benign and inflammatory tumors are common. Malignancies like lymphomas and metastases are most commonly seen in subjects of more than 60 years [8]. A case of post-traumatic carotido-cavernous fistula is seen in our study. It is an abnormal communication between the carotid artery and cavernous veins. A part from the carotido-cavernous fistula, trauma can also cause dural fistula, orbital hematoma, or orbital emphysema [1,9].

The other etiologies of proptosis not found in our study are bone malformations or craniosynostoses like in Crouzon syndrome, Apert syndrome, Pfeiffer syndrome.

\section{Conclusion}

Proptosis is relatively common symptom and clinical and etiological investigation leads to various diseases. Dysthyroidism is the most frequent etiology of proptosis.

\section{References}

1. Ducasse A (2009) Pratical management of proptosis. J Fr Ophtalmol 32: 581-588. [Crossref]

2. Camezind P, Robert PY, Adenis J (2004) Clinicalsigns of dysthyroidorbitopathy. $J \mathrm{Fr}$ Ophtalmol 24: 810-814. [Crossref]

3. Leray B, Imbert P, Thouvenin D, Boutault F, Caron P (2013) Diagnosis and treatment of dysthyroid orbitopathy : a multidisciplinary disease. $J$ Fr Ophtalmol 36: 874-885. [Crossref]

4. Wiersinga WM, Bartalena L (2002) Epidemiology and prevention of Graves ophthalmopathy. Thyroid 12: 855-860. [Crossref]

5. Marius N, Stan MN, Garrity JA, Bahn RS (2012) The Evaluation and Treatment of Graves Ophthalmopathy. Med Clin North Am 96: 311-328. [Crossref]

6. Mouriaux F,Rysanek B, Babin E, Cattoir V (2012) Orbital cellulitis. J Fr Ophtalmol 35: 52-57.

7. Wane AM, Ba EA, Ndoye-Roth PA, Kameni A, Demedeiros ME, et al. (2005) Senegaleseexperience of orbital cellulitis. J Fr Ophtalmol 28: 1089-1094. [Crossref]

8. Ruban JM, Baggio E (2009) Tumoral exophthamitis. J Fr Ophtalmol 32: 600-609

9. Vonor K, Sewa EV, Tchaou M, Dzidzinyo K, Amedome KM, et al. (2014) Posttraumaticcarotido-cavernous sinus fistula: a case report. J Afr Imag Med 4: 54-58.

Copyright: (C2017 Kokou V. This is an open-access article distributed under the terms of the Creative Commons Attribution License, which permits unrestricted use, distribution, and reproduction in any medium, provided the original author and source are credited. 